\title{
Pharmacologic management of bone-related complications and bone metastases in postmenopausal women with hormone receptor-positive breast cancer
}

This article was published in the following Dove Press journal:

Breast Cancer:Targets and Therapy

3 May 2016

Number of times this article has been viewed

\author{
Denise A Yardley ${ }^{1,2}$ \\ 'Sarah Cannon Research Institute, \\ Nashville, TN, USA; ${ }^{2}$ Tennessee \\ Oncology, Nashville, TN, USA
}

\begin{abstract}
There is a high risk for bone loss and skeletal-related events, including bone metastases, in postmenopausal women with hormone receptor-positive breast cancer. Both the disease itself and its therapeutic treatments can negatively impact bone, resulting in decreases in bone mineral density and increases in bone loss. These negative effects on the bone can significantly impact morbidity and mortality. Effective management and minimization of bone-related complications in postmenopausal women with hormone receptor-positive breast cancer remain essential. This review discusses the current understanding of molecular and biological mechanisms involved in bone turnover and metastases, increased risk for bone-related complications from breast cancer and breast cancer therapy, and current and emerging treatment strategies for managing bone metastases and bone turnover in postmenopausal women with hormone receptor-positive breast cancer.
\end{abstract}

Keywords: breast cancer, bone metastases, hormone receptor-positive, bone-related complications, interventions, management and management strategies, estrogen receptor-positive

\section{Introduction}

Excluding skin cancers, breast cancer is the most frequently diagnosed cancer in US women; it is estimated that breast cancer will be diagnosed in more than 246,600 women in 2016 and that more than 40,450 will eventually die from their disease. ${ }^{1}$ Although the 5 -year survival rate of patients with localized breast cancer is high (99\%), the 5-year survival rate of patients with distant metastatic disease is $26 \%{ }^{2}$

Approximately $70 \%$ of breast cancers are hormone receptor-positive $(\mathrm{HR}+)^{3}$; for these, antiestrogen treatment strategies are recommended. Third-generation aromatase inhibitors (AIs) are standard first-line treatment for postmenopausal women with HR+ early or advanced breast cancer. ${ }^{4}$ AIs have demonstrated improvements in progression-free survival (PFS) and time to progression but have demonstrated only modest benefits in overall survival (OS) versus other endocrine therapies, including tamoxifen..$^{5-9}$ Unfortunately, endocrine therapies have limited long-term efficacy due to development of resistance. ${ }^{10-12}$

Exemestane is a steroidal AI that was initially approved as first-line treatment for postmenopausal women with advanced breast cancer; it is also indicated for the treatment of those with disease progression following tamoxifen therapy. ${ }^{13}$ Based on evidence of increased signaling through the PI3K/AKT/mammalian target of rapamycin pathway in hormone-resistant metastatic breast cancer $(\mathrm{MBC}),{ }^{14-16}$ the combination of exemestane 
plus everolimus, a mammalian target of rapamycin inhibitor, as a treatment for advanced breast cancer has been explored. Results of the Phase III Breast Cancer Trials of Oral Everolimus-2 (BOLERO-2) demonstrated that everolimus plus exemestane was effective in prolonging PFS, leading to approval in postmenopausal women with $\mathrm{HR}+$ /human epidermal growth factor receptor 2-negative advanced breast cancer following progression on nonsteroidal AIs. ${ }^{4,17-19}$ Other US Food and Drug Administration-approved agents have also been effective as monotherapy in tumors exhibiting disease progression. Based on results from the Phase III Evaluation of Faslodex versus Exemestane Clinical Trial and Comparison of Faslodex in Recurrent or Metastatic Breast Cancer studies, ${ }^{20,21}$ monotherapy with fulvestrant, a selective estrogen receptor downregulator, has been approved for postmenopausal women with HR+ $\mathrm{MBC}$ whose disease progressed on previous endocrine therapies. $^{22}$ Other combination endocrine strategies, including the cyclin-dependent kinase 4/6 inhibitors, are under evaluation for patients with endocrine-resistant MBC. ${ }^{23,24}$ Palbociclib, a cyclindependent kinase 4/6 inhibitor, was recently approved for use in combination with letrozole, but only as initial endocrine-based therapy in patients with MBC. . $3,24^{24}$

Given that 61 years is the median age at initial diagnosis of all-stage breast cancer, ${ }^{2}$ many postmenopausal women with diagnoses of breast cancer may already have age-associated bone loss and may require or have been initiated on pharmacologic interventions. Patients with breast cancer are at increased risk for bone loss and fracture compared with age-matched women without cancer. ${ }^{25}$ Additionally, evidence suggests that both chemotherapeutic and antiestrogen agents, to which many patients have been exposed during the disease course, contribute to detrimental bone effects, ${ }^{26,27}$ this is most notable with endocrine therapies, such as AIs and even tamoxifen, which are known to exacerbate bone-related complications because they may increase bone mineral loss. ${ }^{28-30}$ These observations highlight the need to effectively manage bone-related complications in postmenopausal women with HR+ breast cancer.

This review discusses the current understanding of molecular mechanisms involved in bone turnover and metastases, increased risk for bone-related complications as a result of age and breast cancer, therapies used to treat breast cancer, and current and emerging treatment strategies for managing bone metastases and bone turnover.

\section{Current understanding of bone biology and breast cancer}

Bone is continually remodeled by interactions among bone matrix-producing osteoblasts, bone resorption-associated osteoclasts, and resident bone osteocytes. ${ }^{31}$ Estrogen depletion, which occurs in menopause and breast cancer, induces preosteoblasts and osteocytes to secrete the receptor activator of nuclear factor-kappa B ligand (RANK-L), resulting in activation of osteoclast precursors and mature osteoclasts. ${ }^{31-33}$ Activated osteoclasts accelerate bone resorption and remodeling, causing increased bone turnover. ${ }^{31-33}$

Bone remodeling in patients with bone $\mathrm{MBC}$ predominantly uses activated osteoclasts mainly involving RANK-L, parathyroid hormone-related peptide, osteoprotegrin (OPG), and transforming growth factor beta. ${ }^{34,35}$ When tumor cells invade bone, they produce parathyroid hormone-related peptide, which in turn stimulates the upregulation of RANK-L expression by preosteoblasts and downregulates the expression of OPG (OPG normally acts to inhibit RANK-L function); this drives the stimulation of osteoclasts and leads to excessive bone resorption and destruction. ${ }^{34,35}$ Tumor cells also secrete a number of other factors that increase osteoclast formation, including interleukin-6, prostaglandin $\mathrm{E}_{2}$, tumor necrosis factor, and macrophage colony-stimulating factor. ${ }^{35}$ These additional factors further increase RANK-L expression, resulting in RANK-L acting on osteoclast precursors to increase osteoclast production. ${ }^{35}$ Osteoclastic activity in turn increases the production of factors that increase parathyroid hormonerelated peptide production, including but not exclusive to transforming growth factor beta, insulin-like growth factors, platelet-derived growth factor, and bone morphogenetic proteins. ${ }^{35}$ Therefore, the increased RANK-L/OPG ratio activates osteoclasts and bone resorption while releasing the growth factors from the bone matrix that can stimulate tumor growth. ${ }^{34,35}$ Consequently, tumor cells and osteoclasts engage in a self-perpetuating cycle, increasing bone absorption and tumor growth. ${ }^{34,35}$ In patients with bone metastases, increased RANK-L can increase bone destruction and result in significant skeletal-related events (SREs), such as spinal cord compression and pathologic fractures. ${ }^{34}$ Bone is the predominant, and often the first, site of breast cancer metastasis; $50 \%$ to $70 \%$ of women who experience metastases present with bone metastases during their disease course. ${ }^{34,36,37}$ Bone metastases often occur in load-bearing bones and patients are therefore at an increased risk of bone fracture if they develop in the femoral neck and shaft or the pelvis. ${ }^{36}$ Other consequences of bone metastases include bone deformity with vertebral body collapse or compression, hypercalcemia, leukoerythroblastic anemia, and nerve compression syndromes, such as spinal cord compression, that can lead to pain, debilitation, and kyphosis. ${ }^{36}$ 


\section{Bone-related complications caused by treatment}

Osteoporosis affects 200 million women worldwide and is responsible for more than 8.9 million fractures annually; one in three women aged $>50$ years will experience an osteoporotic fracture. ${ }^{38,39}$ The incidence of this disease increases with age in women, affecting $\sim 10 \%, 20 \%, 40 \%$, and $67 \%$ of those aged $60,70,80$, and 90 years, respectively. ${ }^{38}$ Bone mineral density (BMD) scans, known as dual-energy x-ray absorptiometry scans, are used to diagnose osteoporosis. The US Preventive Services Task Force recommends dual-energy $\mathrm{x}$-ray absorptiometry scans for those aged $\geq 65$ years, ${ }^{40}$ although many women are diagnosed with breast cancer prior to reaching this age. Changes in bone turnover markers are used to monitor osteoporosis treatment. BAP, a glycoprotein attached to the surface of osteoblasts, and procollagen type I N-terminal propeptide (PINP), a peptide secreted by osteoblasts, are markers routinely used to measure osteoblastic activity, whereas C-terminal telopeptide (CTX) is a peptide cleaved by osteoclasts and a common marker for bone resorption. ${ }^{41}$

The personal and economic toll of osteoporosis is evident in Europe, where disability due to osteoporosis is greater than that caused by cancers (with the exception of lung cancer). ${ }^{39}$ These findings are loosely paralleled in the US population, where the average length of stay in hospital in 2010 was greater for patients suffering from osteoporotic-related fractures in the neck of the femur (5.8 days on average) compared to that for heart disease (4.6 days), myocardial infarction (5.4 days), and diabetes (4.6 days). ${ }^{42}$ In line with these data, osteoporosis and osteopenia are considered major public health threats for nearly 44 million women and men aged $\geq 50$ years in the USA. ${ }^{43}$ The impact of a timely and effective breast cancer diagnosis and its subsequent treatment can thus be significant in helping to ameliorate the patient's risks associated with osteoporosis and reduce the incidence of general bone health-related issues in breast cancer.

AIs deplete circulating estrogen ${ }^{44}$ and can negatively impact bone remodeling; this decreases BMD and increases bone loss ${ }^{45}$ which is estimated to be twofold greater than menopause-related bone loss. ${ }^{46-48}$ The consequences of decreased BMD and increased bone loss as a result of AI therapy include greater risk for osteoporosis and bone fracture ${ }^{30,46,49-51}$ and potentially increased risk for morbidity and mortality. ${ }^{52}$ Adjuvant studies confirm that AIs increase fracture risk, with an incidence of $7 \%$ after a median of 30 months of treatment with exemestane and an incidence of $9 \%$ to $11 \%$ after up to 5 years of treatment with letrozole or anastrozole..$^{50,53,54}$

Other endocrine agents used in the treatment of breast cancer differ from AIs in their impact on bone. Possibly because of its estrogenic agonistic effects, tamoxifen has been shown to improve BMD in postmenopausal women, ${ }^{45,55,56}$ but similar effects in premenopausal women are not seen. ${ }^{57}$ Few results have been reported with fulvestrant; however, in a small 18-month substudy that included 14 patients treated with fulvestrant as first-line therapy in locally advanced breast cancer, fulvestrant did not increase the bone turnover markers BAP, PINP, and CTX. ${ }^{58}$ Given the small number of patients in this trial, it is unclear what impact the seemingly bone-neutral effects of fulvestrant might have in countering or not worsening detrimental bone loss experienced with earlier adjuvant therapies, but it is worth additional exploration.

\section{Pharmacologic interventions to manage bone-related complications}

Therapies decreasing bone resorption or stimulating new bone formation include bisphosphonates and the monoclonal antibody to human RANK-L. ${ }^{59-61}$ Bisphosphonates are a class of drugs that bind bone minerals where they are absorbed by mature osteoclasts; this results in osteoclast apoptosis and suppression of bone resorption. ${ }^{31}$ Use of bisphosphonates in other cancer types, such as osteolytic disease in multiple myeloma and metastatic bone disease in other solid tumors, is increasingly common, particularly to prevent skeletal complications, relieve bone pain, and prevent treatmentinduced bone loss. ${ }^{34}$ Denosumab is a monoclonal antibody that binds to human RANK-L and prevents osteoclast formation, function, and survival and reduces cancer-induced bone destruction. ${ }^{31}$ The optimal pharmacologic management of bone-related complications in breast cancer is debated, but it is largely derived from clinician experiences with these complications in aging and osteoporosis. ${ }^{62}$

In early breast cancer, postmenopausal women who initiate adjuvant therapy with AIs often receive calcium and vitamin D supplements, and additional bisphosphonate therapy is considered to avoid a progression to osteoporosis in patients with osteopenia. ${ }^{63}$ High weekly doses of vitamin $\mathrm{D}_{2}$ or $\mathrm{D}_{3}$ are effective at reducing AI-induced musculoskeletal symptoms when given after the initiation of AI therapy. ${ }^{64,65}$ Bisphosphonates reduce AI-induced bone loss and improve BMD in patients with early breast cancer. ${ }^{66-71}$ Similarly, denosumab improves BMD in postmenopausal women with early breast cancer who are undergoing adjuvant AI therapy. ${ }^{72}$ The bisphosphonates zoledronate and pamidronate and the 
RANK-L inhibitor denosumab are approved for the treatment of advanced breast cancer and bone metastases ${ }^{59-61}$ and are recommended for the prevention and treatment of SREs., ${ }^{4,73}$

\section{Bisphosphonates}

In the Phase III Protocol 19 trial of the Aredia Breast Cancer Study Group in women with MBC who had previously received chemotherapy, pamidronate prolonged median time to first skeletal complication versus placebo (13.9 vs 7.0 months; $P>0.001) .{ }^{74}$ The Phase II Protocol 18 trial from the same group demonstrated that pamidronate decreased skeletal morbidity rate and increased time to first SRE versus placebo, and a sustained reduction in bone turnover markers (ie, urinary calcium, hydroxyproline, creatinine, and serum bone alkaline phosphatase) was achieved with pamidronate. ${ }^{75}$ There were no differences in adverse effects between the placebo and drug groups in the use of pamidronate. ${ }^{74,75}$ Anemia, thrombocytopenia, hyperphosphatemia, myalgias, arthralgias, and influenza-like symptoms were slightly higher in the pamidronate group. ${ }^{74}$ Other trials found that vomiting and fatigue were the only adverse effects that were slightly higher in the pamidronate group than the placebo group. ${ }^{75}$ None of these differences reached a level of statistical significance. $^{74,75}$

Similarly, zoledronate reduced skeletal complications in a randomized, placebo-controlled registration trial in Japanese women with breast cancer-related bone metastases. ${ }^{76}$ Compared with placebo, zoledronate reduced the risk for SREs at 1 year by $39 \%(P=0.027) .{ }^{76}$ Median time to first SRE was significantly longer for zoledronate recipients than placebo recipients (not reached vs 364 days; $P=0.007$ ) ${ }^{76}$ Tolerability of zoledronate was within the same safety profile as placebo, with less than a $15 \%$ frequency of reported adverse events by any group. ${ }^{76}$ The most frequent adverse events suspected to be drug-related were pyrexia, nausea, and fatigue. ${ }^{76}$ Direct comparison of zoledronate with pamidronate in a Phase III trial of patients with bone MBC demonstrated no significant difference in the incidence of SREs. ${ }^{77}$ However, a subgroup analysis of patients with at least one osteolytic lesion at study entry suggested zoledronate was superior to pamidronate in reducing skeletal complications. ${ }^{78}$ Data for other bisphosphonates not licensed in the USA for use in patients with breast cancer are also available; in particular, they show that ibandronate reduced the risk for vertebral fractures and new bone events, and reduced the skeletal morbidity period rate (defined as 12-week periods without new SREs) versus placebo in Phase III trials in patients with bone metastases from breast cancer. ${ }^{79,80}$

\section{Monoclonal antibody to RANK-L}

In a Phase III trial in patients with advanced breast cancer with at least one bone metastasis, denosumab was found to be superior to zoledronate in delaying or preventing SREs (hazard ratio, $0.82 ; P=0.01$ ). ${ }^{81}$ Bone turnover markers were also suppressed to a greater extent with denosumab than with zoledronate $(P>0.001) .{ }^{81}$ Reported adverse events were similar between treatment groups where the most serious adverse event reported was anemia (5.7\% of patients). The denosumab group reported a higher incidence of hypocalcemia than the zoledronate group, while the latter group reported a higher incidence of adverse renal events and acute phase reactions. ${ }^{82}$ The discontinuation of denosumab showed that its effects on BMD and bone turnover markers are fully reversible and able to be restored with retreatment when no increase in fracture risk was observed after discontinuation. ${ }^{83-85}$ Furthermore, patients receiving denosumab were found to exhibit higher BMD than patients in the corresponding placebo group. ${ }^{83,84}$ Consistent with these data, a meta-analysis of several randomized trials comparing bisphosphonates with placebo, bisphosphonates with other bisphosphonates, and bisphosphonates with denosumab supports the role of bisphosphonates and denosumab in reducing the risk for SREs in patients with breast cancer-related bone metastases, and indicates that these therapies were also effective in delaying the time to SREs. ${ }^{34}$

\section{Everolimus/Exemestane combination}

Everolimus was approved in combination with exemestane for postmenopausal women with HR+/HER2- advanced breast cancer that progressed on previous nonsteroidal AI therapy. ${ }^{17}$ Exemestane reportedly increases bone resorption, ${ }^{86}$ though a preclinical study suggested that everolimus directly inhibits bone resorption by osteoclasts. ${ }^{87}$ Based on these insights, an exploratory analysis of the BOLERO-2 trial data was performed to evaluate bone turnover markers. ${ }^{88}$ Results showed increased bone turnover marker levels in exemestane recipients at 6 and 12 weeks compared with baseline, whereas bone turnover marker levels decreased in everolimus plus exemestane recipients. ${ }^{88}$ Bone-related adverse events, including fractures, osteonecrosis, and osteoporosis, were similar between treatment groups where the safety profile was acceptable and manageable. ${ }^{88}$ These observations suggest that everolimus may prevent bone turnover associated with AI therapy, but this should be verified in prospective studies.

To further investigate the long-term effects of everolimus on bone health, the Phase IIIb study in postmenopausal women with HR+ advanced breast cancer treated with everolimus 
plus exemestane was recently completed (NCT01626222) (Table 1). ${ }^{89,90}$ Primary end point was overall response rate after 6 months. Secondary end points included PFS after 6 and 12 months, overall response rate after 12 months, OS, quality of life, health utilities, and health care resources. Exploratory objectives included assessment of bone turnover biomarkers (ie, PINP, CTX, OPG, RANK-L, vitamin $\mathrm{D}$, follicle-stimulating hormone, and estradiol). Preliminary exploratory data on bone biomarkers suggest that everolimus reduces bone turnover and reverses the increase in bone absorption associated with endocrine therapy. ${ }^{89}$ The ability of everolimus to reduce bone resorption could be linked to its antitumor properties or everolimus may have a direct effect on AI-induced bone resorption; however, additional analyses of the data are needed to confirm the finding. ${ }^{88}$

\section{Investigational agents}

Other therapies currently under investigation include the small molecule tyrosine kinase inhibitors vandetanib (vascular endothelial growth factor receptor and epidermal growth factor receptor), dasatinib (breakpoint cluster region-Abelson murine leukemia and Src), and cabozantinib (c-MET and vascular endothelial growth factor receptor 2). Data are available only for vandetanib, which was evaluated in a Phase II trial of postmenopausal women with bone-only or bone-predominant $\mathrm{HR}+\mathrm{MBC}$, and demonstrated that adding vandetanib to fulvestrant did not improve biomarker response, PFS, or OS versus fulvestrant alone (NCT00811369). ${ }^{91}$ At least two Phase II trials with secondary end points of bone turnover are evaluating dasatinib in combination with endocrine therapy. Results are eagerly awaited for a completed Phase II trial (NCT00754325) evaluating dasatinib in combination with fulvestrant in patients with $\mathrm{HR}+$ advanced breast cancer previously treated with an AI. In the second trial (NCT00696072), final efficacy results demonstrated that dasatinib as first- or second-line therapy with letrozole in postmenopausal women with HR+/HER2- breast cancer did not appear to improve clinical benefit rate (primary end point) but it prolonged PFS. ${ }^{92}$ Cabozantinib is under evaluation in a Phase II trial (NCT01441947) in women with HR+ MBC with bone involvement, with bone imaging response rate the primary end point and bone turnover a secondary end point.

\section{Antitumor effects of bone- modifying agents in patients with breast cancer}

Although bone-modifying agents are used as supplementary therapy to prevent or reduce the incidence of SREs in patients with malignant bone disease, recent evidence from multiple myeloma and other solid tumors suggests that these agents may also demonstrate antitumor activity. ${ }^{93}$ Preliminary evidence of the effects of these agents in delaying disease

Table I Summary of compounds in development for the management of bone-related complications and bone metastases in postmenopausal women with hormone receptor-positive breast cancer

\begin{tabular}{|c|c|c|c|c|c|}
\hline Agent & Clinical trial identifier & Phase & Design & End points & Status \\
\hline \multicolumn{6}{|c|}{ mTOR inhibitor } \\
\hline Everolimus & EVE NCTOI 626222 & Illb & $\begin{array}{l}E V E+E X E \text { vs } P B O+E X E \text { in } \\
\text { patients with } A B C \text { or } M B C\end{array}$ & $\begin{array}{l}\text { Primary: ORR } \\
\text { Exploratory: Bone } \\
\text { turnover markers }\end{array}$ & Completed \\
\hline \multicolumn{6}{|c|}{ Tyrosine kinase inhibitors } \\
\hline Cabozantinib & NCT0I44I947 & $\|$ & $\begin{array}{l}\mathrm{CAB}+\mathrm{FUL} \text { in } \mathrm{HR}+\mathrm{BC} \text { that } \\
\text { has spread to the bone }\end{array}$ & $\begin{array}{l}\text { Primary: Bone imaging } \\
\text { response rate } \\
\text { Secondary: Bone turnover }\end{array}$ & Ongoing \\
\hline Dasatinib & NCT00754325 & II & $\begin{array}{l}\text { DAS+FUL vs FUL in } \\
\text { patients with } A B C\end{array}$ & $\begin{array}{l}\text { Primary: PFS } \\
\text { Secondary: Change in } \\
\text { bone markers, effect on } \\
\text { bone pain, BMD changes }\end{array}$ & Completed \\
\hline Dasatinib & NCT00696072 & II & $\begin{array}{l}\text { DAS+LET vs LET in } \\
\text { MBC }\end{array}$ & $\begin{array}{l}\text { Primary: CBR } \\
\text { Secondary: Change in } \\
\text { bone markers, effect on } \\
\text { bone pain, BMD changes }\end{array}$ & Completed \\
\hline Vandetanib & NCT008II 369 & II & $\begin{array}{l}\text { VAN+FUL vs PBO+FUL } \\
\text { in patients with bone only or } \\
\text { bone-predominant } \mathrm{HR}+\mathrm{MBC}\end{array}$ & $\begin{array}{l}\text { Primary: Change in NTx } \\
\text { level }\end{array}$ & Completed \\
\hline
\end{tabular}

Abbreviations: ABC, advanced breast cancer; BC, breast cancer; BMD, bone mineral density; CAB, cabozantinib; CBR, clinical benefit rate; DAS, dasatinib; EVE, everolimus; EXE, exemestane; FUL, fulvestrant; HR+, hormone receptor-positive; LET, letrozole; MBC, metastatic breast cancer; mTOR, mammalian target of rapamycin; NTx, N-terminal telopeptide; ORR, overall response rate; PBO, placebo; PFS, progression-free survival; VAN, vandetanib. 
progression in patients with early breast cancer is emerging, ${ }^{94}$ and initial reports of their antitumor effects in advanced disease are available. ${ }^{95,96}$

Results from preclinical studies provide a potential mechanism for antitumor activity. ${ }^{48}$ Preclinical evidence suggests that the nitrogen-containing bisphosphonates zoledronate and pamidronate block the enzyme farnesyl diphosphatase synthase, resulting in inhibition of tumor cell adhesion, migration, invasion, and proliferation and inducing cell death in a wide range of cell lines. ${ }^{97}$ Nitrogen-containing bisphosphonate-mediated reductions in skeletal tumor burden in animal models have been attributed to their antiresorptive activity because they deprive tumor cells of growth factors required for seeding and growth of tumor cells in the bone marrow. ${ }^{98,99}$

Studies of bisphosphonates in the treatment of early breast cancer provide conflicting evidence for a potential antitumor effect, with improvements in disease-free survival (DFS), OS, or both observed in some studies and either no effect or a detrimental effect observed in others. ${ }^{67,94,96,100-104}$ Recent meta-analyses have indicated a positive effect of adjuvant bisphosphonate therapy on DFS, bone recurrence, OS, and breast cancer-specific survival in postmenopausal women. ${ }^{105-107}$ These findings are corroborated by Early Breast Cancer Trialists' Collaborative Group et al, ${ }^{108}$ which noted that adjuvant bisphosphonate therapies significantly reduce bone recurrence while subgroup analyses demonstrated this benefit in postmenopausal women only with the additional benefit of significantly reducing distant recurrence, breast cancer mortality, and overall mortality. These reductions were apparent regardless of chemotherapy status, suggesting bisphosphonates to be additive to chemotherapy and vice versa. The effect of different bisphosphonate regimens remains unclear. ${ }^{108}$ In contrast, a Cochrane review based on a meta-analysis of seven randomized trials in early breast cancer indicated insufficient evidence to arrive at a conclusion regarding the efficacy of bisphosphonates in reducing the incidence of bone metastases or improving survival. ${ }^{34}$ Denosumab is under evaluation in two Phase III trials (NCT01077154 and NCT00556374) as neoadjuvant and adjuvant therapy for up to 5 years in women with high-risk early breast cancer. Both trials include DFS, OS, and bone metastasis-free survival as end points.

Data on the antitumor effects of bone-modifying agents in advanced breast cancer are less extensive than they are in earlier disease. In a recent study of breast cancer patients with bone marrow-detected tumor cells, zoledronate was more effective than placebo in eliminating these cells. ${ }^{109}$ In a randomized trial of patients with early-stage breast cancer with identified tumor cells in the bone marrow, the risk for distant metastases was significantly lower with adjuvant clodronate than standard follow-up (13\% vs 29\%; $P<0.001$ ), as was the incidence of osseous and visceral metastases ( $8 \%$ vs $17 \%$ and $8 \%$ vs $19 \%$, respectively; $P=0.003$ for both). ${ }^{95}$

Although the bone-protective effects of everolimus remain to be confirmed, initial reports of its antitumor effects on bone metastases are available. In a Phase II hypothesisgenerating study, everolimus single-agent activity on bone metastases was noted in patients whose bone metastases had not progressed after 8 weeks of treatment. ${ }^{110}$ This randomized, double-blind, placebo-controlled, Phase II study demonstrated that treatment continuation with everolimus was beneficial in patients with HER2- breast cancer and bone metastases. ${ }^{110}$ An exploratory analysis of results from the BOLERO-2 trial showed that progressive disease in bone occurred in $13.0 \%$ of patients treated with everolimus plus exemestane versus $18.8 \%$ treated with exemestane alone. ${ }^{88}$ The median PFS in patients with bone-only metastasis treated with everolimus plus exemestane and exemestane alone was 12.9 and 5.3 months, respectively, translating to a $67 \%$ reduction in risk of progression with everolimus therapy (hazard ratio, $0.33 ; P<0.05) .{ }^{111}$ This reduction in risk of progression was similar to the $55 \%$ reduction in risk of progression observed in the overall population of the trial at a median follow-up of 18 months (hazard ratio, $0.45 ; P<0.0001) .{ }^{19}$ These findings suggest that everolimus may help lower disease progression in bone, but larger prospective trials are needed to confirm this observation.

\section{Complications of treatment with bone-modifying agents}

Nephrotoxicity, hypocalcemia, and osteonecrosis of the jaw (ONJ) are some clinically important adverse events observed with bone-modifying agents. ${ }^{112}$ Nephrotoxicity typically manifests as serum creatinine elevations, occurring in $2 \%$ to $8 \%$ of patients treated with intravenous bisphosphonates ${ }^{112}$ and in $\sim 5 \%$ of those treated with denosumab. ${ }^{81}$ Risk for nephrotoxicity is increased in patients with preexisting renal dysfunction, and bisphosphonates are not recommended for patients with creatinine clearance less than $30 \mathrm{~mL} / \mathrm{min} .{ }^{113}$ Hypocalcemia occurs in up to $5 \%$ of patients treated with bisphosphonates or denosumab; therefore, calcium and vitamin D supplementation and regular monitoring of serum calcium are recommended for these patients. ${ }^{12}$ ONJ is a 
rare but distressing complication, reported in $1.2 \%$ to $2.4 \%$ of patients treated with bisphosphonates ${ }^{112}$ and $\sim 2 \%$ of patients treated with denosumab. ${ }^{81}$ Risk factors for $\mathrm{ONJ}$ include use of high-potency aminobisphosphonates (ie, nitrogen-containing bisphosphonates that have significantly increased antiresorptive potencies compared to non-nitrogencontaining bisphosphates), prolonged treatment, concurrent chemotherapy, underlying dental disease, and invasive dental procedures; the incidence of ONJ may be as high as $10 \%$ in patients with multiple risk factors. ${ }^{112,114}$ Risk for ONJ may be mitigated by pretreatment dental assessments (with any required interventions completed before treatment initiation), limitation of dental and jaw bone trauma during treatment, and regular dental monitoring. ${ }^{115}$ Additionally, intravenous bisphosphonates are associated with acute-phase reactions consisting of fever, myalgia, bone pain, and fatigue in up to a third of patients; these reactions typically resolve within 72 hours and can be managed with supportive measures. ${ }^{112}$ Conversely, oral bisphosphonates are associated with significant gastrointestinal toxicity (ie, nausea, vomiting, epigastric pain, and esophagitis). ${ }^{12}$

\section{Conclusion}

Although postmenopausal women with HR+ breast cancer have a better prognosis than postmenopausal women with other breast cancer subtypes, they are at high risk for bone loss and SREs. The efficacy of bisphosphonates in preventing bone loss with chemotherapy and AI therapy in both premenopausal and postmenopausal women has been demonstrated. Although the effect of adding bisphosphonates to neoadjuvant chemotherapy regimens to improve clinical outcomes is unclear, previous studies suggest that the use of bisphosphonates in this setting may have a positive effect on pathological response. ${ }^{101,116}$ Direct comparison of available agents is limited by variations in dosing across studies and requires further investigation.

Bone-modifying agents, including bisphosphonates and denosumab, are recommended as supplementary therapies for minimizing bone remodeling and increasing bone mass in patients at high risk for fracture. Given that 61 years is the median age of women at initial diagnosis of breast cancer, a substantial portion of these patients will already be experiencing normal age-related effects of bone loss. Results from clinical trials investigating the antitumor effects of antiresorptive therapies have been conflicting but generally support a small absolute improvement in OS, with the largest treatment impact on reductions in the recurrence of bone metastasis.
These observations highlight the need for novel therapies that are effective in minimizing bone loss, preventing new bone metastases, and improving the outcomes of patients with HR+ breast cancer. In order to achieve these goals in postmenopausal women with HR+ advanced breast cancer, oncologists should carefully assess the safety and efficacy of agents that protect and prevent disease progression in the bone to appropriately incorporate them into treatment regimens.

\section{Acknowledgments}

Tricia Newell, PhD, and Matthew Grzywacz, PhD (ApotheCom, Yardley, PA, USA), provided writing and editorial assistance that supported the author in the development of this manuscript. This writing and editorial assistance was funded by Novartis Pharmaceuticals Corporation.

\section{Disclosure}

Denise A. Yardley, MD, serves as a consultant to Novartis Pharmaceuticals Corporation. The author reports no other conflicts of interest in this work.

\section{References}

1. American Cancer Society. Cancer Facts and Figures 2016. Available from: http://www.cancer.org/acs/groups/content/@research/documents/ document/acspc-047079.pdf. Accessed March 22, 2016.

2. American Cancer Society. Breast Cancer Facts and Figures 2015-2016. Available from: http://www.cancer.org/acs/groups/content/@research/ documents/document/acspc-046381.pdf. Accessed March 29, 2016.

3. Mao C, Yang ZY, He BF, et al. Toremifene versus tamoxifen for advanced breast cancer. Cochrane Database Syst Rev. 2012;7:CD008926.

4. National Comprehensive Cancer Network Inc. NCCN Clinical Practice Guidelines in Oncology. Breast Cancer. Version 1. Washington: National Comprehensive Cancer Network Inc; 2014.

5. Nabholtz JM, Buzdar A, Pollak M, et al. Anastrozole is superior to tamoxifen as first-line therapy for advanced breast cancer in postmenopausal women: results of a North American multicenter randomized trial. Arimidex Study Group. J Clin Oncol. 2000;18(22): 3758-3767.

6. Nabholtz JM, Bonneterre J, Buzdar A, Robertson JF, Thurlimann B. Anastrozole (Arimidex) versus tamoxifen as first-line therapy for advanced breast cancer in postmenopausal women: survival analysis and updated safety results. Eur J Cancer. 2003;39(12):1684-1689.

7. Paridaens RJ, Dirix LY, Beex LV, et al. Phase III study comparing exemestane with tamoxifen as first-line hormonal treatment of metastatic breast cancer in postmenopausal women: The European Organisation for Research and Treatment of Cancer Breast Cancer Cooperative Group. J Clin Oncol. 2008;26(30):4883-4890.

8. Mouridsen H, Gershanovich M, Sun Y, et al. Phase III study of letrozole versus tamoxifen as first-line therapy of advanced breast cancer in postmenopausal women: analysis of survival and update of efficacy from the International Letrozole Breast Cancer Group. J Clin Oncol. 2003;21(11):2101-2109.

9. Gibson L, Lawrence D, Dawson C, Bliss J. Aromatase inhibitors for treatment of advanced breast cancer in postmenopausal women. Cochrane Database Syst Rev. 2009;4:CD003370.

10. Osborne CK, Schiff R. Mechanisms of endocrine resistance in breast cancer. Annu Rev Med. 2011;62:233-247. 
11. Chlebowski RT. Changing concepts of hormone receptor-positive advanced breast cancer therapy. Clin Breast Cancer. 2013;13(3): $159-166$.

12. Barrios C, Forbes JF, Jonat W, et al. The sequential use of endocrine treatment for advanced breast cancer: where are we? Ann Oncol. 2012;23(6):1378-1386.

13. Aromasin (exemestane tablets) [package insert]. New York, NY: Pharmacia \& Upjohn Company; 2014.

14. Tokunaga E, Kimura Y, Mashino K, et al. Activation of PI3K/Akt signaling and hormone resistance in breast cancer. Breast Cancer. 2006;13(2):137-144.

15. Miller TW, Hennessy BT, Gonzalez-Angulo AM, et al. Hyperactivation of phosphatidylinositol-3 kinase promotes escape from hormone dependence in estrogen receptor-positive human breast cancer. J Clin Invest. 2010;120(7):2406-2413.

16. Beeram M,TanQT,Tekmal RR, RussellD, MiddletonA, DeGraffenriedLA. Akt-induced endocrine therapy resistance is reversed by inhibition of mTOR signaling. Ann Oncol. 2007;18(8):1323-1328.

17. Afinitor (everolimus) tablets for oral administration. Afinitor Disperz (everolimus tablets for oral suspension) [package insert]. East Hanover, NJ: Novartis Pharmaceuticals Corporation; February 2016.

18. Baselga J, Campone M, Piccart M, et al. Everolimus in postmenopausal hormone receptor-positive advanced breast cancer. $N$ Engl $J$ Med. 2012;366(6):520-529.

19. Yardley DA, Noguchi S, Pritchard KI, et al. Everolimus plus exemestane in postmenopausal patients with $\mathrm{HR}(+)$ breast cancer: BOLERO-2 final progression-free survival analysis. Adv Ther. 2013;30(10):870-884.

20. Chia S, Gradishar W, Mauriac L, et al. Double-blind, randomized placebo controlled trial of fulvestrant compared with exemestane after prior nonsteroidal aromatase inhibitor therapy in postmenopausal women with hormone receptor-positive, advanced breast cancer: results from EFECT. J Clin Oncol. 2008;26(10):1664-1670.

21. Di Leo A, Jerusalem G, Petruzelka L, et al. Results of the CONFIRM phase III trial comparing fulvestrant $250 \mathrm{mg}$ with fulvestrant $500 \mathrm{mg}$ in postmenopausal women with estrogen receptor-positive advanced breast cancer. J Clin Oncol. 2010;28(30):4594-4600.

22. Faslodex (fulvestrant) injection [package insert]. Wilmington, DE: AstraZeneca Pharmaceuticals LP; 2012.

23. Ibrance (palbociclib) capsules, for oral use [package insert]. New York, NY: Pfizer Labs; 2015.

24. Finn RS, Crown JP, Lang I, et al. The cyclin-dependent kinase 4/6 inhibitor palbociclib in combination with letrozole versus letrozole alone as first-line treatment of oestrogen receptor-positive, HER2-negative, advanced breast cancer (PALOMA-1/TRIO-18): a randomised phase 2 study. Lancet Oncol. 2015;16(1):25-35.

25. Chen Z, Maricic M, Bassford TL, et al. Fracture risk among breast cancer survivors: results from the Women's Health Initiative Observational Study. Arch Intern Med. 2005;165(6):552-558.

26. Vehmanen L, Saarto T, Elomaa I, Makela P, Valimaki M, Blomqvist C. Long-term impact of chemotherapy-induced ovarian failure on bone mineral density (BMD) in premenopausal breast cancer patients. The effect of adjuvant clodronate treatment. Eur J Cancer. 2001;37(18):2373-2378.

27. Fuleihan G, Salamoun M, Mourad YA, et al. Pamidronate in the prevention of chemotherapy-induced bone loss in premenopausal women with breast cancer: a randomized controlled trial. J Clin Endocrinol Metab. 2005;90(6):3209-3214.

28. Goss PE, Ingle JN, Martino S, et al. A randomized trial of letrozole in postmenopausal women after five years of tamoxifen therapy for earlystage breast cancer. N Engl J Med. 2003;349(19):1793-1802.

29. Santen RJ. Clinical review: effect of endocrine therapies on bone in breast cancer patients. J Clin Endocrinol Metab. 2011;96(2):308-319.

30. Mincey BA, Duh MS, Thomas SK, et al. Risk of cancer treatmentassociated bone loss and fractures among women with breast cancer receiving aromatase inhibitors. Clin Breast Cancer. 2006;7(2):127-132.

31. Hanley DA, Adachi JD, Bell A, Brown V. Denosumab: mechanism of action and clinical outcomes. Int J Clin Pract. 2012;66(12):1139-1146.
32. Manolagas SC. Birth and death of bone cells: basic regulatory mechanisms and implications for the pathogenesis and treatment of osteoporosis. Endocr Rev. 2000;21(2):115-137.

33. Weitzmann MN, Pacifici R. Estrogen deficiency and bone loss: an inflammatory tale. J Clin Invest. 2006;116(5):1186-1194.

34. Wong MH, Stockler MR, Pavlakis N. Bisphosphonates and other bone agents for breast cancer. Cochrane Database Syst Rev. 2012;2:CD003474.

35. Roodman GD. Mechanisms of bone metastasis. $N$ Engl J Med. 2004;350(16):1655-1664.

36. Mundy GR. Metastasis to bone: causes, consequences and therapeutic opportunities. Nat Rev Cancer. 2002;2(8):584-593.

37. Coleman RE. Metastatic bone disease: clinical features, pathophysiology and treatment strategies. Cancer Treat Rev. 2001;27(3):165-176.

38. Kanis JA. Assessment of Osteoporosis at the Primary Health Care Level. WHO Scientific Group Technical Report. Available from: http://www. iofbonehealth.org/sites/default/files/WHO_Technical_Report-2007.pdf. 2007. Accessed May 13, 2015.

39. Johnell O, Kanis JA. An estimate of the worldwide prevalence and disability associated with osteoporotic fractures. Osteoporos Int. 2006;17(12):1726-1733.

40. Gralow JR, Biermann JS, Farooki A, et al. NCCN Task Force Report: Bone health in cancer care. J Natl Compr Canc Netw. 2013;11 (Suppl 3): S1-S50.

41. Seibel MJ. Biochemical markers of bone turnover: part I: biochemistry and variability. Clin Biochem Rev. 2005;26(4):97-122.

42. US Department of Health and Human Services. National Hospital Discharge Survey; 2010. Available from: ftp://ftp.cdc.gov/pub/Health_ Statistics/NCHS/Dataset_Documentation/NHDS/NHDS_2010_ Documentation.pdf; 2012. Accessed February 11, 2016.

43. International Osteoporosis Foundation. Facts and Statistics. Available from: http://www.iofbonehealth.org/facts-statistics. 2015. Accessed May 18, 2015.

44. Fabian CJ. The what, why and how of aromatase inhibitors: hormonal agents for treatment and prevention of breast cancer. Int J Clin Pract. 2007;61(12):2051-2063.

45. Rizzoli R, Body JJ, De CA, et al. Guidance for the prevention of bone loss and fractures in postmenopausal women treated with aromatase inhibitors for breast cancer: an ESCEO position paper. Osteoporos Int. 2012;23(11):2567-2576.

46. Perez EA, Josse RG, Pritchard KI, et al. Effect of letrozole versus placebo on bone mineral density in women with primary breast cancer completing 5 or more years of adjuvant tamoxifen: a companion study to NCIC CTG MA.17. J Clin Oncol. 2006;24(22): $3629-3635$

47. Eastell R, Adams JE, Coleman RE, et al. Effect of anastrozole on bone mineral density: 5-year results from the anastrozole, tamoxifen, alone or in combination trial 18233230. J Clin Oncol. 2008;26(7):1051-1057.

48. Eastell R, Hannon RA, Cuzick J, et al. Effect of an aromatase inhibitor on bmd and bone turnover markers: 2-year results of the Anastrozole, Tamoxifen, Alone or in Combination (ATAC) trial (18233230). J Bone Miner Res. 2006;21(8):1215-1223.

49. Houston KE, Thomson DB. Aromatase inhibitors: what is the true cost? Intern Med J. 2011;41(2):139-140.

50. Coleman RE, Banks LM, Girgis SI, et al. Skeletal effects of exemestane on bone-mineral density, bone biomarkers, and fracture incidence in postmenopausal women with early breast cancer participating in the Intergroup Exemestane Study (IES): a randomised controlled study. Lancet Oncol. 2007;8(2):119-127.

51. Arimidex, Tamoxifen, Alone or in Combination (ATAC) Trialists' Group, Forbes JF, Cuzick J, et al. Effect of anastrozole and tamoxifen as adjuvant treatment for early-stage breast cancer: 100-month analysis of the ATAC trial. Lancet Oncol. 2008;9(1):45-53.

52. Bliuc D, Nguyen ND, Milch VE, Nguyen TV, Eisman JA, Center JR. Mortality risk associated with low-trauma osteoporotic fracture and subsequent fracture in men and women. JAMA. 2009;301(5):513-521. 
53. Howell A, Cuzick J, Baum M, et al. Results of the ATAC (Arimidex, Tamoxifen, Alone or in Combination) trial after completion of 5 years' adjuvant treatment for breast cancer. Lancet. 2005;365(9453): 60-62.

54. Rabaglio M, Sun Z, Price KN, et al. Bone fractures among postmenopausal patients with endocrine-responsive early breast cancer treated with 5 years of letrozole or tamoxifen in the BIG 1-98 trial. Ann Oncol. 2009;20(9):1489-1498.

55. Love RR, Mazess RB, Barden HS, et al. Effects of tamoxifen on bone mineral density in postmenopausal women with breast cancer. $N$ Engl J Med. 1992;326(13):852-856.

56. Ding H, Field TS. Bone health in postmenopausal women with early breast cancer: how protective is tamoxifen? Cancer Treat Rev. 2007;33(6):506-513.

57. Powles TJ, Hickish T, Kanis JA, Tidy A, Ashley S. Effect of tamoxifen on bone mineral density measured by dual-energy $\mathrm{x}$-ray absorptiometry in healthy premenopausal and postmenopausal women. J Clin Oncol. 1996;14(1):78-84.

58. Agrawal A, Hannon RA, Cheung KL, Eastell R, Robertson JF. Bone turnover markers in postmenopausal breast cancer treated with fulvestrant - a pilot study. Breast. 2009;18(3):204-207.

59. Zometa (zoledronic acid) injection [package insert]. East Hanover, NJ: Novartis Pharmaceuticals Corp; 2015.

60. Aredia (pamidronate disodium for injection) for intravenous infusion [package insert]. East Hanover, NJ: Novartis Pharmaceuticals Corp; 2011.

61. Xgeva (denosumab) injection, for subcutaneous use [package insert]. Thousand Oaks, CA: Amgen Inc; June 2015.

62. Gnant M. Role of bisphosphonates in postmenopausal women with breast cancer. Cancer Treat Rev. 2014;40(3):476-484.

63. Bosco D. Osteoporosis and aromatase inhibitors: experience and future prospects. Clin Cases Miner Bone Metab. 2012;9(2):89-91.

64. Rastelli AL, Taylor ME, Gao F, et al. Vitamin D and aromatase inhibitor-induced musculoskeletal symptoms (AIMSS): a phase II, double-blind, placebo-controlled, randomized trial. Breast Cancer Res Treat. 2011;129(1):107-116.

65. Khan QJ, Reddy PS, Kimler BF, et al. Effect of vitamin D supplementation on serum 25-hydroxy vitamin D levels, joint pain, and fatigue in women starting adjuvant letrozole treatment for breast cancer. Breast Cancer Res Treat. 2010;119(1):111-118.

66. Nuzzo F, Gallo C, Lastoria S, et al. Bone effect of adjuvant tamoxifen, letrozole or letrozole plus zoledronic acid in early-stage breast cancer: the randomized phase 3 HOBOE study. Ann Oncol. 2012;23(8):2027-2033.

67. Coleman R, De BR, Eidtmann H, et al. Zoledronic acid (zoledronate) for postmenopausal women with early breast cancer receiving adjuvant letrozole (ZO-FAST study): final 60-month results. Ann Oncol. 2013;24(2):398-405.

68. Brufsky AM, Harker WG, Beck JT, et al. Final 5-year results of Z-FAST trial: adjuvant zoledronic acid maintains bone mass in postmenopausal breast cancer patients receiving letrozole. Cancer. 2012;118(5):1192-1201.

69. Llombart A, Frassoldati A, Paija O, et al. Immediate administration of zoledronic acid reduces aromatase inhibitor-associated bone loss in postmenopausal women with early breast cancer: 12-month analysis of the E-ZO-FAST trial. Clin Breast Cancer. 2012;12(1):40-48.

70. Lester JE, Dodwell D, Purohit OP, et al. Prevention of anastrozoleinduced bone loss with monthly oral ibandronate during adjuvant aromatase inhibitor therapy for breast cancer. Clin Cancer Res. 2008;14(19):6336-6342.

71. McCloskey E, Paterson A, Kanis J, Tahtela R, Powles T. Effect of oral clodronate on bone mass, bone turnover and subsequent metastases in women with primary breast cancer. Eur J Cancer. 2010;46(3):558-565.

72. Ellis GK, Bone HG, Chlebowski R, et al. Randomized trial of denosumab in patients receiving adjuvant aromatase inhibitors for nonmetastatic breast cancer. J Clin Oncol. 2008;26(30):4875-4882.
73. Van Poznak CH, Temin S, Yee GC, et al. American Society of Clinical Oncology executive summary of the clinical practice guideline update on the role of bone-modifying agents in metastatic breast cancer. J Clin Oncol. 2011;29(9):1221-1227.

74. Hortobagyi GN, Theriault RL, Lipton A, et al. Long-term prevention of skeletal complications of metastatic breast cancer with pamidronate. Protocol 19 Aredia Breast Cancer Study Group. J Clin Oncol. 1998;16(6):2038-2044.

75. Theriault RL, Lipton A, Hortobagyi GN, et al. Pamidronate reduces skeletal morbidity in women with advanced breast cancer and lytic bone lesions: a randomized, placebo-controlled trial. Protocol 18 Aredia Breast Cancer Study Group. J Clin Oncol. 1999;17(3):846-854.

76. Kohno N, Aogi K, Minami H, et al. Zoledronic acid significantly reduces skeletal complications compared with placebo in Japanese women with bone metastases from breast cancer: a randomized, placebo-controlled trial. J Clin Oncol. 2005;23(15):3314-3321.

77. Rosen LS, Gordon D, Kaminski M, et al. Zoledronic acid versus pamidronate in the treatment of skeletal metastases in patients with breast cancer or osteolytic lesions of multiple myeloma: a phase III, double-blind, comparative trial. Cancer J. 2001;7(5):377-387.

78. Rosen LS, Gordon DH, Dugan W Jr, et al. Zoledronic acid is superior to pamidronate for the treatment of bone metastases in breast carcinoma patients with at least one osteolytic lesion. Cancer. 2004;100(1):36-43.

79. Body JJ, Diel IJ, Lichinitser MR, et al. Intravenous ibandronate reduces the incidence of skeletal complications in patients with breast cancer and bone metastases. Ann Oncol. 2003;14(9):1399-1405.

80. Body JJ, Diel IJ, Lichinitzer M, et al. Oral ibandronate reduces the risk of skeletal complications in breast cancer patients with metastatic bone disease: results from two randomised, placebo-controlled phase III studies. Br J Cancer. 2004;90(6):1133-1137.

81. Stopeck AT, Lipton A, Body JJ, et al. Denosumab compared with zoledronic acid for the treatment of bone metastases in patients with advanced breast cancer: a randomized, double-blind study. J Clin Oncol. 2010;28(35):5132-5139.

82. Lipton A, Fizazi K, Stopeck AT, et al. Superiority of denosumab to zoledronic acid for prevention of skeletal-related events: a combined analysis of 3 pivotal, randomised, phase 3 trials. Eur J Cancer. 2012;48(16):3082-3092.

83. Miller PD, Bolognese MA, Lewieki EM, et al. Effect of denosumab on bone density and turnover in postmenopausal women with low bone mass after long-term continued, discontinued, and restarting of therapy: a randomized blinded phase 2 clinical trial. Bone. 2008;43(2):222-229.

84. Bone HG, Bolognese MA, Yuen CK, et al. Effects of denosumab treatment and discontinuation on bone mineral density and bone turnover markers in postmenopausal women with low bone mass. J Clin Endocrinol Metab. 2011;96(4):972-980.

85. Gotter AL, Webber AL, Coleman PJ, Renger JJ, Winrow CJ. International Union of Basic and Clinical Pharmacology. LXXXVI. Orexin receptor function, nomenclature and pharmacology. Pharmacol Rev. 2012;64(3):389-420.

86. Hadji P, Ziller M, Kieback DG, et al. The effect of exemestane or tamoxifen on markers of bone turnover: results of a German sub-study of the Tamoxifen Exemestane Adjuvant Multicentre (TEAM) trial. Breast. 2009;18(3):159-164.

87. Kneissel M, Luong-Nguyen NH, Baptist M, et al. Everolimus suppresses cancellous bone loss, bone resorption, and cathepsin $\mathrm{K}$ expression by osteoclasts. Bone. 2004;35(5):1144-1156.

88. Gnant M, Baselga J, Rugo HS, et al. Effect of everolimus on bone marker levels and progressive disease in bone in BOLERO-2. J Natl Cancer Inst. 2013;105(9):654-663.

89. Hadji P, Tesch H, Fasching PA, et al. 4EVER: Does mTOR inhibition have a major clinical impact on bone health in postmenopausal women with hormone receptor positive $(\mathrm{HR}+)$ locally advanced breast cancer treated with everolimus (EVE) in combination with exemestane (EXE)? Presented at: San Antonio Breast Cancer Symposium; December 14, 2013; San Antonio, TX, USA; abstr P6-06-32rt. 
90. Tesch H, Fasching PA, Hadji P, et al. 4EVER - A phase IIIb, multi-center, open label study for postmenopausal women with estrogen receptor positive locally advanced or metastatic breast cancer (BC) treated with everolimus (EVE) in combination with exemestane (EXE). Presented at: San Antonio Breast Cancer Symposium; December 12, 2013; San Antonio, TX, USA; abstr OT2-6-09.

91. Clemons MJ, Cochrane B, Pond GR, et al. Randomised, phase II, placebo-controlled, trial of fulvestrant plus vandetanib in postmenopausal women with bone only or bone predominant, hormone-receptorpositive metastatic breast cancer (MBC): the OCOG ZAMBONEY study. Breast Cancer Res Treat. 2014;146(1):153-162.

92. Paul D, Vukelja SJ, Holmes FA, et al. Letrozole plus dasatinib improves progression-free survival (PFS) in hormone receptor-positive, HER-2 negative postmenopausal metastatic breast cancer (MBC) patients receiving first-line aromatase inhibitor (AI) therapy. Presented at: San Antonio Breast Cancer Symposium; December 12, 2013; San Antonio, TX, USA; abstr S3-07.

93. Costa L, Harper P, Coleman RE, Lipton A. Anticancer evidence for zoledronic acid across the cancer continuum. Crit Rev Oncol Hematol. 2011;77 (Suppl 1):S31-S37.

94. Gnant M, Mlineritsch B, Schippinger W, et al. Endocrine therapy plus zoledronic acid in premenopausal breast cancer. $N$ Engl J Med. 2009;360(7):679-691.

95. Diel IJ, Solomayer EF, Costa SD, et al. Reduction in new metastases in breast cancer with adjuvant clodronate treatment. $N$ Engl J Med. 1998;339(6):357-363.

96. Saarto T, Blomqvist C, Virkkunen P, Elomaa I. Adjuvant clodronate treatment does not reduce the frequency of skeletal metastases in node-positive breast cancer patients: 5-year results of a randomized controlled trial. J Clin Oncol. 2001;19(1):10-17.

97. Coleman R, Gnant M, Morgan G, Clezardin P. Effects of bone-targeted agents on cancer progression and mortality. J Natl Cancer Inst. 2012;104(14):1059-1067.

98. Clezardin P. Bisphosphonates' antitumor activity: an unravelled side of a multifaceted drug class. Bone. 2011;48(1):71-79.

99. Ottewell PD, Deux B, Monkkonen H, et al. Differential effect of doxorubicin and zoledronic acid on intraosseous versus extraosseous breast tumor growth in vivo. Clin Cancer Res. 2008;14(14):4658-4666.

100. Coleman RE, Marshall H, Cameron D, et al. Breast-cancer adjuvant therapy with zoledronic acid. $N$ Engl J Med. 2011;365(15):1396-1405.

101. Coleman RE, Winter MC, Cameron D, et al. The effects of adding zoledronic acid to neoadjuvant chemotherapy on tumour response: exploratory evidence for direct anti-tumour activity in breast cancer. Br J Cancer. 2010;102(7):1099-1105.

102. Paterson AH, Anderson SJ, Lembersky BC, et al. Oral clodronate for adjuvant treatment of operable breast cancer (National Surgical Adjuvant Breast and Bowel Project protocol B-34): a multicentre, placebocontrolled, randomised trial. Lancet Oncol. 2012;13(7):734-742.

103. Powles T, Paterson S, Kanis JA, et al. Randomized, placebo-controlled trial of clodronate in patients with primary operable breast cancer. J Clin Oncol. 2002;20(15):3219-3224.
104. von Minckwitz G, Mobus V, Schneeweiss A, et al. German adjuvant intergroup node-positive study: a phase III trial to compare oral ibandronate versus observation in patients with high-risk early breast cancer. J Clin Oncol. 2013;31(28):3531-3539.

105. Ben-Aharon I, Vidal L, Rizel S, et al. Bisphosphonates in the adjuvant setting of breast cancer therapy - effect on survival: a systematic review and meta-analysis. PLoS One. 2013;8(8):e70044.

106. He M, Fan W, Zhang X. Adjuvant zoledronic acid therapy for patients with early stage breast cancer: an updated systematic review and metaanalysis. J Hematol Oncol. 2013;6(1):80.

107. Coleman R, Gnant M, Paterson T, et al. Effects of bisphosphonate treatment on recurrence and cause-specific mortality in women with early breast cancer: a meta-analysis of individual patient data from randomised trials. Presented at: San Antonio Breast Cancer Symposium; December 12, 2013; San Antonio, TX, USA; abstr S4-S07.

108. Early Breast Cancer Trialists' Collaborative Group (EBCTCG); Coleman R, Powles T, Paterson A, et al. Adjuvant bisphosphonate treatment in early breast cancer: meta-analyses of individual patient data from randomised trials. Lancet. 2015;386(10001):1353-1361.

109. Aft R, Naughton M, Trinkaus K, et al. Effect of zoledronic acid on disseminated tumour cells in women with locally advanced breast cancer: an open label, randomised, phase 2 trial. Lancet Oncol. 2010;11(5):421-428.

110. Maass N, Harbeck N, Mundhenke C, et al. Everolimus as treatment for breast cancer patients with bone metastases only: results of the phase II RADAR study. J Cancer Res Clin Oncol. 2013;139(12):2047-2056.

111. Campone M, Bachelot T, Gnant M, et al. Effect of visceral metastases on the efficacy and safety of everolimus in postmenopausal women with advanced breast cancer: subgroup analysis from the BOLERO-2 study. Eur J Cancer. 2013;49(12):2621-2632.

112. Wallace MS, Irving G, Cowles VE. Gabapentin extended-release tablets for the treatment of patients with postherpetic neuralgia: a randomized, double-blind, placebo-controlled, multicentre study. Clin Drug Investig. 2010;30(11):765-776.

113. Clemons M, Gelmon KA, Pritchard KI, Paterson AH. Bone-targeted agents and skeletal-related events in breast cancer patients with bone metastases: the state of the art. Curr Oncol. 2012;19(5):259-268.

114. Durie BGM, Katz M, Crowley J. Osteonecrosis of the jaw and bisphosphonates. N Engl J Med. 2005;353(1):99-102.

115. Fusco V, Galassi C, Berruti A, et al. Decreasing frequency of osteonecrosis of the jaw in cancer and myeloma patients treated with bisphosphonates: the experience of the oncology network of Piedmont and Aosta valley (north-Western Italy). ISRN Oncol. 2013;2013:672027.

116. Chavez-Macgregor M, Brown E, Lei X, et al. Bisphosphonates and pathologic complete response to taxane- and anthracycline-based neoadjuvant chemotherapy in patients with breast cancer. Cancer. 2012;118(2):326-332.
Breast Cancer: Targets and Therapy

\section{Publish your work in this journal}

Breast Cancer: Targets and Therapy is an international, peerreviewed open access journal focusing on breast cancer research, identification of therapeutic targets and the optimal use of preventative and integrated treatment interventions to achieve improved outcomes, enhanced survival and quality of life for the cancer patient.

\section{Dovepress}

View the full aims and scopes of this journal here. The manuscript management system is completely online and includes a very quick and fair peer-review system, which is all easy to use. Visit http:// www.dovepress.com/testimonials.php to read real quotes from published authors. 